\title{
Occurrence of antibiotics in water, sediments, aquatic plants, and animals from Baiyangdian Lake in North China
}

\author{
Wenhui Li ${ }^{a}$, Yali Shi ${ }^{a}$, Lihong Gao ${ }^{a}$, Jiemin Liu ${ }^{b}$, Yaqi Cai ${ }^{\text {a,* }}$ \\ ${ }^{a}$ State Key Laboratory of Environmental Chemistry and Ecotoxicology, Research Center for Eco-Environmental Science, Chinese Academy of Sciences, Beijing 100085, China \\ ${ }^{\mathrm{b}}$ Civil and Environment Engineering School, University of Science and Technology Beijing, Beijing 100083, China
}

\section{H I G H L I G H T S}

- Antibiotics widely existed in the Baiyangdian Lake.

- Geographical differences of antibiotic levels were greatly due to human activities.

- Salvinia natans exhibited strongest bioaccumulation for quinolones.

- Algae and aquatic plants may be at risk of antibiotics in surface water.

\section{A R T I C L E I N F O}

\section{Article history:}

Received 6 February 2012

Received in revised form 16 May 2012

Accepted 16 May 2012

Available online 12 June 2012

\section{Keywords:}

Antibiotics

Quinolones

Sulfonamides

Macrolides

Baiyangdian Lake

\begin{abstract}
A B S T R A C T
This study investigated the presence and distribution of 22 antibiotics, including eight quinolones, nine sulfonamides and five macrolides, in the water, sediments, and biota samples from Baiyangdian Lake, China. A total of 132 samples were collected in 2008 and 2010, and laboratory analyses revealed that antibiotics were widely distributed in the lake. Sulfonamides were the dominant antibiotics in the water (0.86-1563 $\left.\mathrm{ng} \mathrm{L}^{-1}\right)$, while quinolones were prominent in sediments $\left(65.5-1166 \mu \mathrm{g} \mathrm{kg}^{-1}\right)$ and aquatic plants (8.37-6532 $\mu \mathrm{g} \mathrm{kg}^{-1}$ ). Quinolones (17.8-167 $\mu \mathrm{g} \mathrm{kg}^{-1}$ ) and macrolides [from below detection limit (BDL) to $182 \mu \mathrm{g} \mathrm{kg}^{-1}$ ] were often found in aquatic animals and birds. Salvinia natans exhibited the highest bioaccumulation capability for quinolones among three species of aquatic plants. Geographical differences of antibiotic concentrations were greatly due to anthropogenic activities. Sewage discharged from Baoding City was likely the main source of antibiotics in the lake. Risk assessment of antibiotics on aquatic organisms suggested that algae and aquatic plants might be at risk in surface water, while animals were likely not at risk.
\end{abstract}

(c) 2012 Elsevier Ltd. All rights reserved.

\section{Introduction}

Antibiotics, including quinolones (QNs), sulfonamides (SAs) and macrolides (MCs), are extensively used to treat infectious diseases of humans and animals (Kümmerer, 2009). Some of them are also widely used as growth promoters in aquaculture, agriculture and livestock farming (Cruz Moreno-Bondi et al., 2009). However, many antibiotics cannot be completely absorbed or metabolized, and a considerable fraction has been released into the environment. Although many antibiotics are being degraded at a certain rate, most of them are replaced by ongoing wide use, so they are pseudopersistent in the environment (Khetan and Collins, 2007).

As an emerging class of environmental contaminants (Matamoros and Bayona, 2006; Yang et al., 2011), antibiotics have attracted increasing attention due to their undesirable effects on ecosystems

\footnotetext{
* Corresponding author. Tel./fax: +86 1062849182.

E-mail address: caiyaqi@rcees.ac.cn (Y. Cai).
}

and the health of humans and animals (Sapkota et al., 2008). Common antibiotics such as quinolones, sulfonamides and macrolides have been found in wastewater (Rosal et al., 2010), sewage sludge (Radjenovic et al., 2009), sediments (Zhou et al., 2011), soils (Blackwell et al., 2009), and foods (Kan and Petz, 2000) in many regions and countries. Many rivers and oceans have serious problems of antibiotic contamination, and antibiotics in water may be potentially bioaccumulated in aquatic organisms (Edwards et al., 2009). In the Mekong Delta of Vietnam, some SAs and MCs were detected in the river and canals at $7-360 \mathrm{ng} \mathrm{L}^{-1}$ (Managaki et al., 2007). Analyses have shown that water in Haihe River in China contains $24-385 \mathrm{ng} \mathrm{L}^{-1}$ of SAs (Luo et al., 2011). However, very limited information is available for the occurrence and distribution of antibiotics in freshwater lakes (Nakata et al., 2005).

Baiyangdian Lake, the largest natural freshwater body in North China, is facing serious pollution. Many pollutants are widespread in Baiyangdian Lake (Chen et al., 2008; Hu et al., 2010; Guo et al., 2011; Pei et al., 2011). However, antibiotic pollution in this area 
has not been investigated. The aim of this study was to investigate the occurrence and distribution of antibiotics in the water, sediments, hydrophytes and animals of Baiyangdian Lake. We also investigated the potential hazards of selected antibiotics on the aquatic organisms. To our best knowledge, this is the first study demonstrating the ubiquitous occurrence of antibiotics in a freshwater lake in China.

\section{Materials and methods}

\subsection{Reagents}

HPLC-grade methanol and acetonitrile were purchased from Fisher Scientific (Pittsburgh, PA, USA); formic acid (98\%) was purchased from Fluka; ammonium formate (99\%) and ammonium hydroxide (v/v, 50\%) were purchased from Alfa Aesar. De-ionized (DI) water $\left(>18.2 \mathrm{M} \Omega \mathrm{cm}^{-1}\right)$ was prepared with the Milli-Q Advantage A10 system (Millipore, USA).

Sulfathiazole (STZ, 99.0\%), sulfapyridine (SPD, 99.0\%), sulfamethoxazole (SMX, 99.0\%), and sulfamethazine (SMZ, 99.0\%) were purchased from KaSei Industry Co., Ltd. (Tokyo, Japan). Ofloxacin (OFL, 99.9\%), norfloxacin (NOR, 99.9\%), ciprofloxacin (CIP, 99.9\%), sarafloxacin (SAR, 95.0\%), fleroxacin (FLE, 99.5\%), lomefloxacin (LOM, 98.0\%), difloxacin (DIF, 98.0\%), enrofloxacin (ENR, 99.9\%), sulfadiazine (SDZ, 99.7\%), sulfamerazine (SMR, 99.9\%), sulfadimethoxine (SDM, 99.4\%), sulfisoxazole (SIA, 99.0\%), sulfamonomethoxine (SMM, 99.0\%), erythromycin (ERY, 99.1\%), roxithromycin (ROX, 90.0\%), josamycin (JOS, 98.0\%), tylosin (TYL, 82.4\%), and spiramycin (SPI, 88.9\%) were purchased from Sigma-Aldrich (St. Louis, MO, USA).

The isotope-labeled compounds were used as surrogate standards (100.0 $\mu \mathrm{g} \mathrm{L}^{-1}$ in methanol). Norfloxacin- $\mathrm{d}_{5}$ (NOR-d $\mathrm{d}_{5}$ ), ofloxacin- $\mathrm{d}_{3}\left(\mathrm{OFL}-\mathrm{d}_{3}\right)$ and sarafloxacin- $\mathrm{d}_{8}\left(\mathrm{SAR}-\mathrm{d}_{8}\right)$ were purchased from Sigma-Aldrich (St. Louis, MO, USA); sulfamethoxazole-d $\mathrm{d}_{4}$ (SMX$\left.\mathrm{d}_{4}\right)$, sulfamethazine- $\mathrm{d}_{4}\left(S M Z-\mathrm{d}_{4}\right)$, spiramycin $\mathrm{I}-\mathrm{d}_{3}\left(\right.$ SPI $\left.\mathrm{I}-\mathrm{d}_{3}\right)$, and erythromycin- ${ }^{13} \mathrm{C}, \mathrm{d}_{3}$ (ERY- ${ }^{13} \mathrm{C}, \mathrm{d}_{4}$ ) were purchased from Toronto Research Chemicals (Oakville, ON, Canada).

\subsection{Sampling area and sample collection}

Baiyangdian Lake, located in Hebei province, is the largest natural freshwater body in North China. It consists of 140 small and shallow lakes that are linked together by thousands of ditches, covering a total of $366 \mathrm{~km}^{2}$ in surface area (Zhuang et al., 2011). It is also an essential natural wetland for groundwater replenishment, flood control and biodiversity preservation in this region.

Sampling was performed twice from Baiyangdian Lake as well as its five upstream rivers in August 2008 and October 2010 (Fig. 1). A total of 18 sediment, 24 plant and 16 animal samples were collected in the first sampling, and 27 water and sediment samples, seven plant and 13 animal samples were collected in the second sampling. Five categories of biota samples were collected from Baiyangdian Lake, including three hydrophyte species [Salvinia natans (Sal), Hydrocharis dubia (Hyd) and Ceratophyllum demersum (Cer)], four crustacean species [crab (Eriocheir sinensis), river snail (Viviparus), shrimp (Macrobrachium nipponense) and lobster (Palinuridae)], seven fish species [topmouth gudgeon (Pseudorasbora parva), loach (Misgurnus anguillicaudatus), yellow catfish (Pelteobagrus fluvidraco), crucian carp (Carassius auratus), common carp (Cyprinus carpio), silver carp (Hypophthalmichthys molitrix) and bluntsnout bream (Megalobrama amblycephala)], one reptile species [turtle (Pelodiscus sinensis)] and two bird species [mallard (Anas platyrhynchos) and Chinese pond heron (Ardeoala bacchus)]. Details of biota samples are shown in Table S1.
All samples were placed on ice and transported to the laboratory after collection as soon as possible. Surface water sample was collected from each sampling site with a stainless steel bucket that had been pre-cleaned with methanol, DI water and rinsed by the sample before collection. Water samples were kept at $4{ }^{\circ} \mathrm{C}$ and target antibiotics were extracted from water samples within one week after sample collection. Sediments were collected with a stainless steel grab from the surface sediment. Then the sediments were freeze-dried, ground and passed through a 55-mesh sieve, and kept at $-20^{\circ} \mathrm{C}$ until the analysis. The aquatic plant samples were washed, cut into small pieces and then freeze-dried for analysis. Fish, turtle and birds were dissected for muscles. Lobster and crab were unshelled for soft tissues. Shrimp and topmouth gudgeon were homogenized due to their small sizes. Finally, the pooled tissues were freeze-dried and wrapped in aluminum foil, and then kept at $-20^{\circ} \mathrm{C}$ until analysis.

\subsection{Sample preparation and analysis}

Chemical analysis was performed following the EPA method 1694 developed by the US Environmental Protection Agency with some modifications (EPA, 2007). Target antibiotics were extracted from water samples using AutoTrace SPE 280 (Dionex, USA) with an Oasis HLB cartridge ( $6 \mathrm{~mL}, 200 \mathrm{mg}$; Waters, USA), and from sediment and biota samples with an ASE 350 pressurized liquid extraction (PLE) system (Dionex, Sunnyvale, CA, USA) and then purified using an HLB cartridge.

Water. Water samples were filtered through nylon film $(0.45 \mu \mathrm{m})$ to remove particles. Before extraction with Oasis HLB cartridge, $0.2 \mathrm{~g}$ of $\mathrm{Na}_{2}$ EDTA, and $20 \mathrm{ng}$ of surrogate standards (norfloxacin- $\mathrm{d}_{5}$, ofloxacin- $\mathrm{d}_{3}$, sarafloxacin- $\mathrm{d}_{8}$, sulfamethoxazole- $\mathrm{d}_{4}$, sulfamethazine- $\mathrm{d}_{4}$, spiramycin $\mathrm{I}-\mathrm{d}_{3}$ and erythromycin-13C $\mathrm{C}_{3}$ ) were added to $200 \mathrm{~mL}$ water sample. The HLB cartridges were conditioned with $5 \mathrm{~mL}$ methanol and $5 \mathrm{~mL}$ DI water. After loading of samples, cartridges were washed with $15 \mathrm{~mL}$ of DI water and vacuum-dried for $20 \mathrm{~min}$. Finally, the cartridges were eluted with $6 \mathrm{~mL}$ of methanol containing 5\% ammonium hydroxide. All the eluates were concentrated to $1 \mathrm{~mL}$ with a stream of nitrogen at $35^{\circ} \mathrm{C}$, and $15 \mu \mathrm{L}$ of this solution was injected into the high-performance liquid chromatography-electrospray ionization tandem mass spectrometry (HPLC-ESI MS/MS) system for analysis.

Sediment, plant and animal samples. A total of $0.1 \mathrm{~g}$ of pretreated lyophilized sample was spiked with $20 \mathrm{ng}$ of internal standard (norfloxacin- $\mathrm{d}_{5}$, ofloxacin- $\mathrm{d}_{3}$, sarafloxacin- $\mathrm{d}_{8}$, sulfamethoxazole$\mathrm{d}_{4}$, sulfamethazine- $\mathrm{d}_{4}$, spiramycin I- $\mathrm{d}_{3}$ and erythromycin-13C $\mathrm{C}_{3}$ ) before being thoroughly mixed with $3 \mathrm{~g}$ of EDTA-washed diatomite from Varian (Walnut Creek, KS, USA). The mixture was put into a $10 \mathrm{~mL}$ stainless steel extraction cell with $100 \%$ methanol as the extracting solvent.

The extraction conditions were as follows: extraction temperature, $70^{\circ} \mathrm{C}$; extraction pressure, $10.34 \mathrm{MPa}$; preheating period, $5 \mathrm{~min}$; static extraction, $10 \mathrm{~min}$; final extraction volume, $60 \mathrm{~mL}$; flush volume $60 \%$ of the cell volume; nitrogen purge, $100 \mathrm{~s}$; and number of extraction cycles, 2.

After extraction, a total of $25 \mathrm{~mL}$ extract was transferred to $100 \mathrm{~mL}$ round-bottom flask, and then concentrated with an RE2000 rotary evaporator (Yarong, Shanghai, China) to a final volume of about $1 \mathrm{~mL}$ at $37{ }^{\circ} \mathrm{C}$ and $0.08 \mathrm{MPa}$. Immediately after concentration, the extract was transferred to a $100 \mathrm{~mL}$ conical tube and then was diluted to a final volume of $100 \mathrm{~mL}$ with DI water.

The SPE procedure was the same as that used for treating water sample. The eluate was concentrated to $1 \mathrm{~mL}$ under a gentle stream of nitrogen at $35^{\circ} \mathrm{C}$ before being dissolved with $1 \mathrm{~mL}$ of a mixture of methanol/aqueous solution of $0.05 \%$ formic acid $(10: 90 \mathrm{v} / \mathrm{v})$. Then the extract was centrifuged for $5 \mathrm{~min}$ at $12000 \mathrm{rpm}$. Finally, the supernatant was filtered through a $0.22 \mu \mathrm{m}$ nylon filter, and 


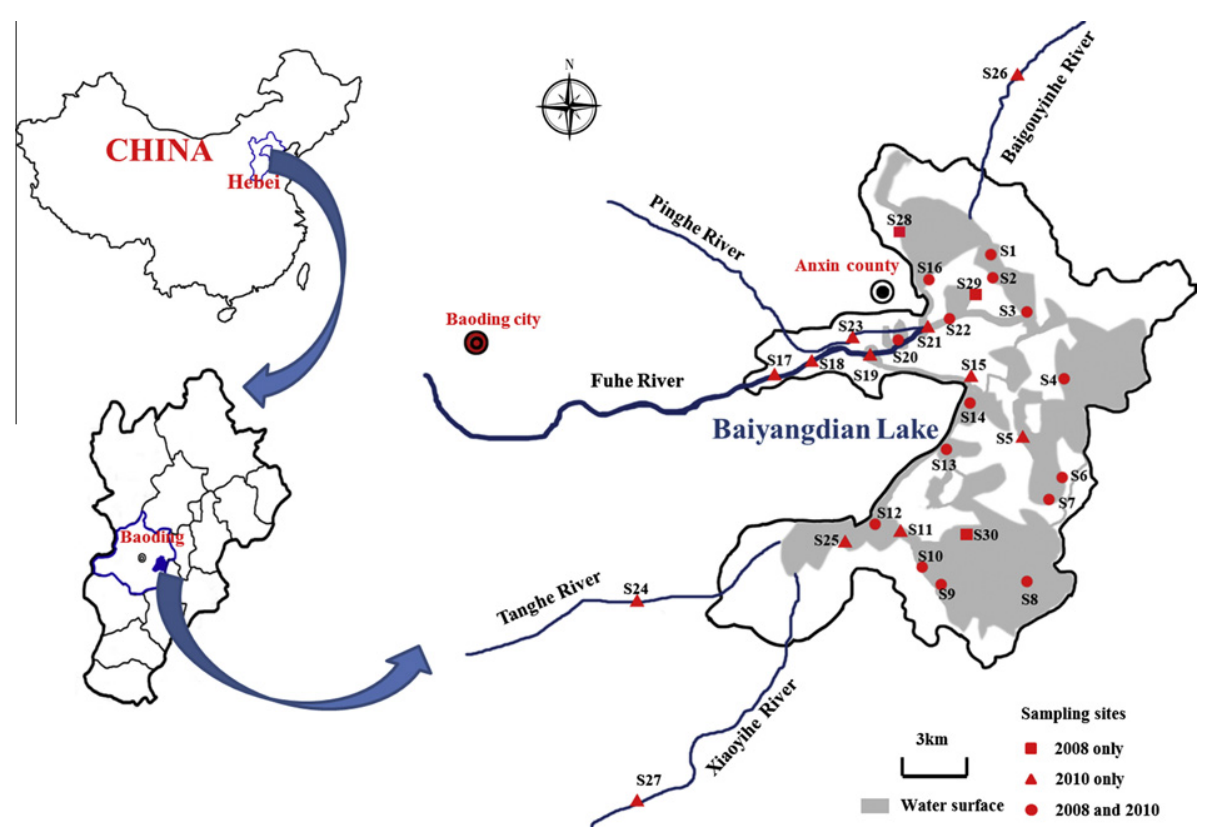

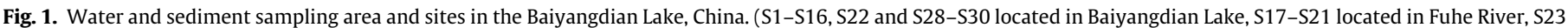
located in Pinghe River, S24 and S25 located in Tanghe River, S26 located in Baigouyin River, and S27 located in Xiaoyi River.)

an aliquot $(15 \mu \mathrm{L})$ was injected into the high-performance liquid chromatography-electrospray ionization tandem mass spectrometry (HPLC-ESI MS/MS) system for analysis.

\subsection{Liquid chromatography/tandem mass spectrometry}

The LC-MS/MS system consisted of an Ultimate 3000 HPLC (Dionex, Sunnyvale, CA, USA) and a triple-quadrupole mass spectrometer (API 3200; Applied Biosystems/MDS SCIEX, US) with electrospray ionization (ESI). The separation was performed at room temperature on an XTerra MS C18 column ( $3 \mu \mathrm{m}, 100 \mathrm{~mm} \times 2 \mathrm{~mm})$ at a flow rate of $0.20 \mathrm{~mL} \mathrm{~min}^{-1}$. Methanol-acetonitrile $(1: 1, \mathrm{~V} / \mathrm{V})$ was used as mobile phase $\mathrm{A}$, and $0.3 \%$ formic acid/water (containing $0.1 \%$ ammonium formate, $\mathrm{V} / \mathrm{V}, \mathrm{pH}=2.9$ ) was used as mobile phase $\mathrm{B}$. The gradient program was as follows: the gradient started with $10 \% \mathrm{~A}$ for $2.0 \mathrm{~min}$, and $\mathrm{A}$ was increased to $70 \%$ in $10.0 \mathrm{~min}$ before being increased to $100 \%$ in $4.0 \mathrm{~min} ; 100 \%$ A was maintained $3.0 \mathrm{~min}$, followed by returning to the initial composition in $0.1 \mathrm{~min}$, which was maintained for $13.9 \mathrm{~min}$. The total run time was $33.0 \mathrm{~min}$

For MS detection, the instrument was operated in positive electrospray ionization and multiple reactions monitoring (MRM) mode. The MS/MS parameters were optimized as follows: curtain gas pressure, $0.14 \mathrm{MPa}$; collision gas pressure, $0.02 \mathrm{MPa}$; ion spray voltage, $5000 \mathrm{~V}$; temperature, $600^{\circ} \mathrm{C}$; gas $1,0.38 \mathrm{MPa}$; and gas 2 , $0.45 \mathrm{MPa}$. Other parameters of MS/MS and ion pair are listed in Table S2.

\subsection{Quality assurance and quality control}

The concentrations were determined using an internal standard method. Ten concentration $[0.01,0.05,0.1,0.5,1,5,10,50,100$, and $500 \mu \mathrm{g} \mathrm{L}^{-1}$ in water-methanol (9:1, v: v)] of individual antibiotics were used as standards, and the linearity of calibration curves was confirmed $\left(r^{2}>0.99\right)$.

The degradation loss during storage was determined as not significant $(<20 \%)$ by measuring the antibiotic concentrations before and after 1 month's storage in the dark at $-20^{\circ} \mathrm{C}$. Field blanks and procedural blanks were analyzed with extraction to control travel contamination and laboratory contamination, and all equipments and containers were rinsed with methanol and water before use to avoid analytical interference and/or cross contamination.

The limits of detections (LODs) and recoveries for water, sediment, plant and Animal are listed in Table S3. LODs are determined as the concentrations at which signal-to-noise ratios $(\mathrm{S} / \mathrm{N})$ were higher than 3. A $10 \mu \mathrm{g} \mathrm{L}^{-1}$ standard was set as the quality control concentration, which was checked every 10 injections to ensure analysis stability and to verify calibration. The calibration curve was used for quantification only when the quality control standard was within $20 \%$ of its initial value.

\subsection{Statistical analysis}

Statistical analyses were performed with IBM PASW Statistics 18.0 (SPSS Inc., 1993-2007). Comparisons of concentrations were performed using Two-Sample Kolmogorov-Smirnov nonparametric tests. It was considered as statistically significant difference when $p<0.05$ for this test. PCA on the analytical data was executed in order to obtain a visual representation of the main characteristics, and the principal components (PCs) were extracted for eigenvalues that were greater than 1 .

\subsection{Risk characterization}

Hazard quotients (HQs) for the aquatic environment are calculated using the following formula:

$\mathrm{HQ}=\mathrm{MEC} / \mathrm{PNEC}$

where MEC is the maximum measured environmental concentration, and PNEC is the predicted no effect concentration in water. The PNEC in water was calculated following the formula:

$\mathrm{PNEC}=\left(\mathrm{LC}_{50}\right.$ or $\left.\mathrm{EC}_{50}\right) / \mathrm{AF}$

where $\mathrm{LC}_{50}$ or $\mathrm{EC}_{50}$ is the lowest median effective concentration value obtained from the available literature, and $\mathrm{AF}$ is an appropriate standard assessment factor (1000) (Park and Choi, 2008). If the value of $\mathrm{HQ}>1$, the ecological impact is expected for the selected antibiotics (Brain et al., 2004; Robinson et al., 2005; Hernando et al., 2006). 


\section{Results and discussion}

\subsection{Antibiotics in water}

The concentrations of antibiotics in surface water from Baiyangdian Lake are summarized in Table 1 . A total of 17 out of the 22 target antibiotics were detected in surface water samples. Concentrations of $\sum$ SAs, $\sum$ QNs and $\sum$ MCs ranged from 0.86 to $1562 \mathrm{ng} \mathrm{L}^{-1}$ (mean $383 \mathrm{ng} \mathrm{L}^{-1}$ ), 6.28 to $212 \mathrm{ng} \mathrm{L}^{-1}$ (mean $60.1 \mathrm{ng} \mathrm{L}^{-1}$ ) and from BDL to $251 \mathrm{ng} \mathrm{L}^{-1}$ (mean $47.2 \mathrm{ng} \mathrm{L}^{-1}$ ), respectively.

Composition distribution of antibiotics in surface water showed that SAs were the predominant antibiotics (78.1\%) in all samples (Fig. 2). They were the most frequently detected antibiotics (2.22-93.3\%) in water because of their heavy use and high watersolubility, indicating extensive SAs pollution in Baiyangdian Lake. SMX was the most abundant with the highest mean concentration of $240 \mathrm{ng} \mathrm{L}^{-1}$, followed by SDZ with a mean concentration of $118 \mathrm{ng} \mathrm{L}^{-1}$, and the two sulfonamides accounted for $93.4 \%$ of $\sum \mathrm{SAs}$ in water. The mean concentrations of SPD, SMM, SMZ and STZ were only $13.0,6.92,5.25$ and $0.08 \mathrm{ng} \mathrm{L}^{-1}$, respectively, although they were frequently found in these water samples. The other three SAs, SMR, SDM and SIA, were not detected in any sample. QNs and MCs were also found in water samples, but only three of them were detected at relative high concentrations in these samples. The average concentrations of NOR, ROX, and ERY in water were 28.6, 27.2, and $19.2 \mathrm{ng} \mathrm{L}^{-1}$, respectively. However, the mean concentrations of other QNs and MCs were below $10.0 \mathrm{ng} \mathrm{L}^{-1}$. Because most QNs are susceptible to photodegradation and easily bind to particulate matter in rivers (Robinson et al., 2005; Thuy et al., 2011), and some MCs are likely to be biodegraded to a great extent (Huang et al., 2001), most of them present at low levels in surface water.

The levels of antibiotic pollution in surface water of Baiyangdian Lake were not very high. These antibiotic concentrations were slightly higher than those previously reported in surface water in
Australia (SMX, median: 8 ng L ${ }^{-1}$; NOR, median: $31 \mathrm{ng} \mathrm{L}^{-1}$; ROX, median: $9 \mathrm{ng} \mathrm{L}^{-1}$ ) (Watkinson et al., 2009) and in South Korean (SMX, mean: $20 \mathrm{ng} \mathrm{L}^{-1}$; ERY, mean: $3.40 \mathrm{ng} \mathrm{L}^{-1}$ ) (Kim et al., 2007). The concentrations of OFL, NOR, CIP, ROX, and ERY in our study were also lower than those detected in Bohai Sea in China (OFL, mean: $390 \mathrm{ng} \mathrm{L}^{-1}$; NOR, mean: $460 \mathrm{ng} \mathrm{L}^{-1}$; CIP, mean: $110 \mathrm{ng} \mathrm{L}^{-1}$; ROX, mean: $113 \mathrm{ng} \mathrm{L}^{-1}$; ERY, mean: $30 \mathrm{ng} \mathrm{L}^{-1}$ ) (Zou et al., 2011).

Among the 27 water samples, the total antibiotic concentrations from Fuhe River (S17-S21, 589-1841 ng L ${ }^{-1}$ ), Baigouyin River (S26, $1612 \mathrm{ng} \mathrm{L}^{-1}$ ) and Xiaoyi River (S27, $833 \mathrm{ng} \mathrm{L}^{-1}$ ) were higher than those in Baiyangdian Lake (S1-S16, 15.9-432 $\mathrm{ng} \mathrm{L}^{-1}$ ), Pinghe River (S23, 91.9 $\mathrm{ng} \mathrm{L}^{-1}$ ) and Tanghe River (S24, S25, 95.6$202 \mathrm{ng} \mathrm{L}^{-1}$ ) (Fig. 3). The highest levels of total antibiotics were found at site 17 (1841 ng L ${ }^{-1}$ ) in Fuhe River. Along the flow direction, the total concentrations of antibiotics tended to decrease in this river. Additionally, the level of antibiotics at site S19 (907 $\mathrm{ng} \mathrm{L}^{-1}$ ) located in Fuhe River was about ten times higher than that of the adjacent site S23 (91.9 $\mathrm{ng} \mathrm{L}^{-1}$ ) located in Pinghe River. As the unique perennial inflowing river of Baiyangdian Lake, Fuhe River may make a significant contribution of antibiotic input to this lake. It has been reported that Fuhe River receives huge amount of wastewater $\left(250000 \mathrm{~m}^{3} \mathrm{~d}^{-1}\right)$ from Baoding City. Therefore, the sewage discharge from Baoding City with over eight million residents (Moiwo et al., 2010) are likely to be the main source of antibiotics in Baiyangdian Lake. We also found that human activities played a key role in the distribution of antibiotics in Baiyangdian Lake. Low levels of total antibiotics in water samples were found in the middle of the lake (S4-S10, 15.9-86.7 $\mathrm{ng} \mathrm{L}^{-1}$ ), where there was little disturbance by human being activities. On the contrary, relatively high levels of antibiotics were found in densely populated scenic spots (S1-S3, 118-432 $\mathrm{ng} \mathrm{L}^{-1}$ ) and lakeshores (S11S16, 227-445 $\mathrm{ng} \mathrm{L}^{-1}$ ). These results showed that Baiyangdian Lake might be influenced to some extent by the wastewater continuously discharged from the local coastal residents and tourists.

Table 1

Concentrations of antibiotics in water, sediment, plants and animals collected from Baiyangdian Lake.

\begin{tabular}{|c|c|c|c|c|c|c|c|c|c|c|c|c|c|c|c|c|c|c|c|c|}
\hline \multirow[t]{2}{*}{ Analytes } & \multicolumn{5}{|c|}{ Water $\left(n=27, \mathrm{ng} \mathrm{L}^{-1}\right)$} & \multicolumn{5}{|c|}{ Sediment $\left(n=45, \mu \mathrm{g} \mathrm{kg}^{-1}\right.$, dry wt) } & \multicolumn{5}{|c|}{ Plants $\left(n=31, \mu \mathrm{g} \mathrm{kg}^{-1}\right.$, dry wt) } & \multicolumn{5}{|c|}{ Animals ( $n=29, \mu \mathrm{g} \mathrm{kg}^{-1}$, dry wt) } \\
\hline & $\operatorname{Max}^{\mathrm{a}}$ & $\operatorname{Min}^{\mathrm{b}}$ & Mean & $\operatorname{Med}^{\mathrm{c}}$ & Fre $^{\mathrm{d}}$ & $\operatorname{Max}$ & Min & Mean & Med & Fre & $\operatorname{Max}$ & Min & Mean & Med & Fre & $\operatorname{Max}$ & Min & Mean & Med & Fre \\
\hline NOR & 156 & $\mathrm{nd}^{\mathrm{e}}$ & 28.6 & 19.9 & 66.7 & 1140 & 49.4 & 267 & 255 & 100 & 220 & nd & 60.7 & 7.80 & 54.8 & 98.4 & nd & 23.8 & 20.9 & 93.1 \\
\hline CIP & 60.3 & nd & 9.45 & 4.55 & 66.7 & 46.0 & nd & 2.49 & nd & 11.1 & 6310 & nd & 627 & 140 & 93.6 & 29.9 & nd & 4.17 & nd & 37.9 \\
\hline DIF & nd & nd & nd & nd & 0.00 & nd & nd & nd & nd & 0.00 & 47.3 & nd & 5.36 & nd & 32.3 & 6.00 & nd & 4.97 & nd & 44.8 \\
\hline ENR & 4.42 & nd & 1.28 & 1.31 & 66.7 & 13.0 & nd & 0.46 & nd & 4.44 & 12.0 & nd & 2.20 & 1.67 & 74.2 & 36.5 & nd & 3.08 & nd & 34.5 \\
\hline FLE & 6.35 & nd & 2.29 & 2.05 & 70.4 & 6.69 & nd & 0.15 & nd & 2.22 & 36.5 & nd & 1.18 & nd & 3.23 & 18.6 & nd & 1.80 & nd & 20.7 \\
\hline OFL & 32.6 & 0.38 & 9.23 & 6.65 & 100 & 362 & nd & 21.0 & 8.64 & 62.2 & 47.1 & 4.3 & 15.3 & 13.9 & 100 & 30.0 & nd & 5.58 & 2.84 & 79.3 \\
\hline LOM & nd & nd & nd & nd & 0.00 & 29.0 & nd & 0.98 & nd & 6.67 & 2.22 & nd & 0.11 & nd & 6.45 & 18.0 & nd & 1.95 & nd & 31.0 \\
\hline SAR & 28.2 & nd & 9.30 & 11.0 & 70.4 & nd & nd & nd & nd & 0.00 & nd & nd & nd & nd & 0.00 & 48.5 & nd & 2.94 & nd & 24.1 \\
\hline STZ & 1.38 & nd & 0.08 & nd & 7.41 & 5.94 & nd & 0.64 & 0.57 & 75.6 & 13.5 & nd & 0.64 & nd & 12.9 & 15.3 & nd & 0.88 & nd & 17.2 \\
\hline SMX & 940 & nd & 240 & 121 & 96.3 & 7.86 & nd & 0.28 & nd & 24.6 & nd & nd & nd & nd & 0.00 & 2.15 & nd & 0.15 & nd & 6.90 \\
\hline SIA & nd & nd & nd & nd & 0.00 & 1.71 & nd & 0.71 & 0.81 & 64.6 & 6.92 & nd & 0.64 & nd & 16.1 & 156 & nd & 12.1 & nd & 48.3 \\
\hline SPD & 85.0 & nd & 13.0 & 2.58 & 63.0 & 1.40 & nd & 0.16 & nd & 24.6 & nd & nd & nd & nd & 0.00 & 0.70 & nd & 0.02 & nd & 3.45 \\
\hline SDM & nd & nd & nd & nd & 0.00 & 0.20 & nd & 0.04 & nd & 26.7 & nd & nd & nd & nd & 0.00 & nd & nd & nd & nd & 0.00 \\
\hline SMZ & 16.1 & nd & 5.25 & 2.68 & 85.2 & 6.92 & nd & 1.47 & 1.08 & 93.3 & 1.98 & nd & 0.38 & 0.18 & 58.1 & 40.6 & nd & 5.03 & 0.73 & 62.1 \\
\hline SDZ & 505 & 0.86 & 118 & 56.0 & 100 & 2.07 & nd & 0.41 & nd & 42.2 & nd & nd & nd & nd & 0.00 & nd & nd & nd & nd & 0.00 \\
\hline SMR & nd & nd & nd & nd & 0.00 & 2.47 & nd & 0.05 & nd & 2.22 & nd & nd & nd & nd & 0.00 & 0.99 & nd & 0.03 & nd & 3.45 \\
\hline SMM & 23.1 & nd & 6.92 & 5.40 & 96.3 & 0.50 & nd & 0.06 & nd & 26.7 & nd & nd & nd & nd & 0.00 & nd & nd & nd & nd & 0.00 \\
\hline SPI & 2.92 & nd & 0.24 & nd & 14.8 & nd & nd & nd & nd & 0.00 & 0.59 & nd & 0.02 & nd & 3.23 & 33.5 & nd & 2.08 & nd & 13.8 \\
\hline JOS & 0.90 & nd & 0.07 & nd & 14.8 & nd & nd & nd & nd & 0.00 & nd & nd & nd & nd & 0.00 & 1.28 & nd & 0.11 & nd & 10.3 \\
\hline TYL & 1.88 & nd & 0.10 & nd & 7.41 & nd & nd & nd & nd & 0.00 & nd & nd & nd & nd & 0.00 & nd & nd & nd & nd & 0.00 \\
\hline ROX & 155 & nd & 27.2 & 2.64 & 92.6 & 302 & nd & 64.9 & 36.4 & 93.3 & 2.65 & nd & 0.21 & nd & 16.1 & 1076 & nd & 52.1 & 2.52 & 65.5 \\
\hline ERY & 121 & nd & 19.5 & 4.94 & 85.2 & 3.04 & nd & 0.59 & 0.42 & 84.4 & 3.40 & nd & 0.39 & nd & 29.0 & 1.80 & nd & 0.50 & 0.54 & 62.1 \\
\hline
\end{tabular}

\footnotetext{
a Maximum.

b Minimum.

c Median.

d Frequency (\%)

e Not detected.
} 


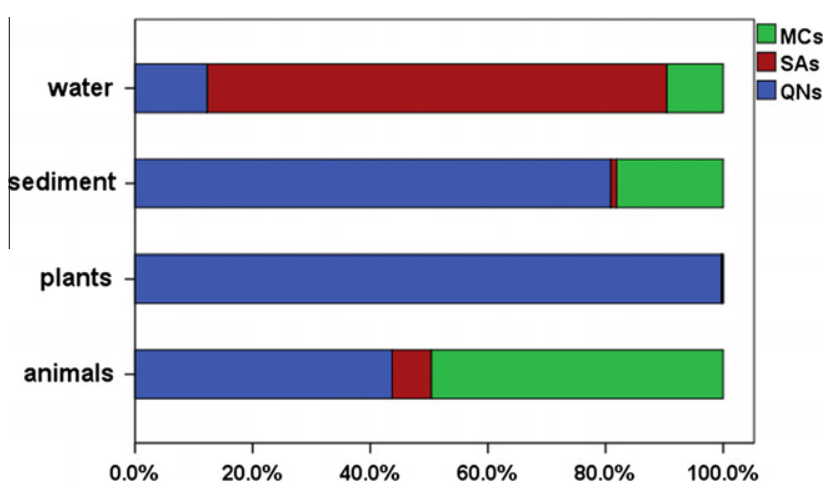

Fig. 2. Composition profiles of compounds in water, sediments, plants and animals.

\subsection{Antibiotics in sediments}

The concentrations of antibiotics in sediment samples from Baiyangdian Lake are summarized in Table 1. A total of 17 antibiotics were detected in the 45 sediment samples. Concentrations of $\sum$ QNs, $\sum$ SAs and $\sum$ MCs ranged from 65.5 to $1166 \mu \mathrm{g} \mathrm{kg}^{-1}$ [mean $293 \mu \mathrm{g} \mathrm{kg}^{-1}$, dry weight (dw)], from BDL to $8.48 \mu \mathrm{g} \mathrm{kg}^{-1}$ (mean $3.82 \mu \mathrm{g} \mathrm{kg}^{-1}$, dw) and from 0.58 to $304 \mu \mathrm{g} \mathrm{kg}^{-1}$ (mean $65.6 \mu \mathrm{g} \mathrm{kg}{ }^{-1}, \mathrm{dw}$ ), respectively. QNs were the predominant antibiotics in sediments (Fig. 2), and $\sum$ QNs, $\sum$ MCs and $\sum$ SAs accounted for $80.9 \%, 18.1 \%$ and $1.06 \%$ of the total antibiotics, respectively.

QNs were the most often detected antibiotics (from $2.22 \%$ to $100 \%$ in sediments. NOR was dominant with the highest mean concentration of $267 \mu \mathrm{g} \mathrm{kg}^{-1}$, followed by OFL and CIP with mean concentrations of 21.0 and $2.49 \mu \mathrm{g} \mathrm{kg}^{-1}$, respectively; and the three QNs accounted for $99.5 \%$ of $\sum$ QNs in sediments. The mean concentrations of LOM, ENR and FLE were below $1 \mu \mathrm{g} \mathrm{kg}^{-1}$, while SAR and DIF were not detected in any sediment sample. Besides QNs, ERY was also detected in sediments with a mean concentration of $64.9 \mu \mathrm{g} \mathrm{kg}^{-1}$. Compared with most MCs and SAs, QNs were strongly adsorbed onto sediments without biodegradation, which promoted their persistence in the environment (Cruz MorenoBondi et al., 2009). The high concentrations of QNs in sediments are believed to be related to their high potential to chelate with
Table 2

Sediment-water distribution coefficient $\left(K_{d, s}\right)$ of antibiotics in Baiyangdian Lake.

\begin{tabular}{lll}
\hline Groups & Analytes & $K_{d, s}$ \\
\hline QNs & NOR & 9360 \\
& CIP & 264 \\
DIF & - \\
& ENR & 362 \\
FLE & 64.8 \\
OFL & 2280 \\
& LOM & - \\
SAR & - \\
SAs & STZ & 8106 \\
& SMX & 1.15 \\
& SIA & - \\
SPD & 12.2 \\
& SDM & - \\
SMZ & 280 \\
& SDZ & 3.51 \\
SMR & - \\
MCs & SMM & 9.37 \\
& SPI & - \\
& JOS & - \\
& TYL & - \\
& ROX & 2385 \\
& ERY & 30.2 \\
\hline
\end{tabular}

cations and to bind with particulate matter, which delay their degradation (Robinson et al., 2005; Tamtam et al., 2008).

The sorption coefficient $K_{d, s}$ is used to describe the reversible sorptive exchange of chemicals between water and sediment (Tolls, 2001). $K_{d, s}$ was calculated according to the following equation: $K_{d, s}=C_{s} / C_{w}$, where $C_{w}$ is the average concentration in water ( $\mathrm{ng} \mathrm{\textrm {L } ^ { - 1 }}$ ), and $C_{s}$ is the average concentration in sediment $\left(\mu \mathrm{g} \mathrm{kg}^{-1}\right)$. The $K_{d, s}$ values in the second sampling are presented in Table 2. NOR, OFL, ENR, CIP, STZ, SMZ, and ROX displayed the highest values of $K_{d, s}$ (range: $264-9364 \mathrm{~L} \mathrm{~kg}^{-1}$ ), suggesting that these antibiotics had tendencies to accumulate in sediments (Yang et al., 2010). FLE, SPD, and ERY displayed intermediate $K_{d, s}$ values ranging from 12.2 to $64.8 \mathrm{~L} \mathrm{~kg}^{-1}$. In contrast, the remaining antibiotics (SMX, SDZ, and SMM) appeared to have little sorption affinities to sediments (Tolls, 2001), as was evidenced by their low values of $K_{d, s}$ (range: $1.15-9.37 \mathrm{~L} \mathrm{~kg}^{-1}$ ). This is in accordance with the conclusion

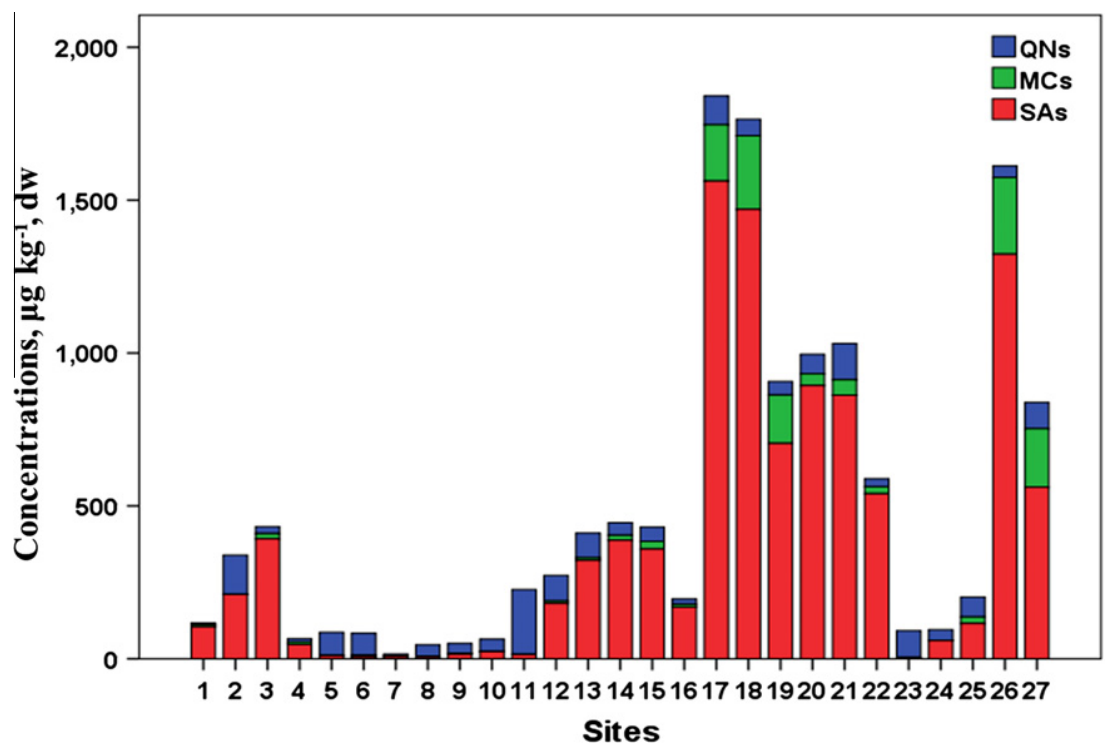

Fig. 3. The concentrations of antibiotics in water samples $\left(\mathrm{ng} \mathrm{L}^{-1}\right)$. 
of previous studies that some SAs are usually relatively mobile (Kim and Carlson, 2005; Batt et al., 2006).

The highest level of total antibiotics $\left(1177 \mu \mathrm{g} \mathrm{kg}^{-1}\right)$ was found at site 25 in Tanghe River near a duckery (Fig. S1), while the lowest level $\left(116 \mu \mathrm{g} \mathrm{kg}^{-1}\right)$ was found at site 27 in Xiaoyi River, where water was mainly supplied by Xidayang Reservoir. As shown in Fig. S1, except the site 25, no considerable differences were observed for the total concentrations of antibiotics in sediments among the other 29 sampling sites.

\subsection{Antibiotics in hydrophyte samples}

Several studies have investigated the potential of antibiotics to be taken up from soil by plants (Boxall et al., 2006; Kümmerer, 2009). However, limited information on antibiotic concentrations in aquatic plants in natural water body is available. The concentrations of antibiotics in aquatic plants from Baiyangdian Lake are summarized in Table 1. A total of 13 antibiotics were detected in most hydrophyte samples, and QNs were the predominant antibiotics (Fig. 2). Concentrations of $\sum$ QNs in hydrophyte ranged from 8.37 to $6532 \mu \mathrm{g} \mathrm{kg}^{-1}$ (mean $711 \mu \mathrm{g} \mathrm{kg}^{-1}, \mathrm{dw}$ ), which were up to two or three orders of magnitude higher than those of $\sum$ SAs (BDL-15.0 $\mu \mathrm{g} \mathrm{kg}^{-1}$, mean: $1.67 \mu \mathrm{g} \mathrm{kg}^{-1}$ ) and $\sum \mathrm{MCs}$ (BDL-6.05 $\mu \mathrm{g} \mathrm{kg}^{-1}$, mean: $0.62 \mu \mathrm{g} \mathrm{kg}^{-1}$ ). CIP was the dominant compound in the aquatic plants (BDL$6310 \mu \mathrm{g} \mathrm{kg}^{-1}$, mean: $627 \mu \mathrm{g} \mathrm{kg}{ }^{-1}$ ), which accounted for $87.8 \%$ of the total concentration of QNs. The mean concentrations of NOR and OFL were only 60.3 and $15.3 \mu \mathrm{g} \mathrm{kg}^{-1}$, respectively, although they were also frequently detected in aquatic plant samples. However, SAs and MCs were detected at very low levels in aquatic plants. These results are similar to those obtained from previous reports that concentrations of some SAs in plant tissues were at low levels (Kümmerer, 2009), and that no TYL was absorbed by some plants in soil (crops corn, green onion, and cabbage) (Kumar et al., 2005).

Significant differences were observed for the antibiotic levels in the three species of aquatic plants $(p<0.05)$ (Fig. S2). The total concentrations of antibiotics in Sal (mean $1769 \mu \mathrm{g} \mathrm{kg}^{-1}$ ) were much higher than those in Cer (mean $253 \mu \mathrm{g} \mathrm{kg}^{-1}$ ) and Hyd (mean $129 \mu \mathrm{g} \mathrm{kg}^{-1}$ ). This result showed that Sal was more susceptible to absorb antibiotic pollutants than Cer and Hyd, and was more sensitive and suitable as an indicator of antibiotic contamination in Baiyangdian Lake.

Bioaccumulation factors (BAFs, ratio of the contaminant concentration in aquatic plant tissue to the contaminant concentration in water) were calculated to evaluate the bioaccumulation of antibiotics in aquatic plants (Kinney et al., 2008). Chemicals were considered to be bio-accumulated if BAFs were higher than 5000 in aquatic organisms (Kelly and Gobas, 2001). When possible, BAFs were calculated for the antibiotics in aquatic plants (Table S4).

In the present study, we found that the mean BAFs were in a range of approximately six orders of magnitude. The BAFs of CIP. NOR and ENR were in the range of $10200-170000 \mathrm{~L} \mathrm{~kg}^{-1}$ (mean: $66300 \mathrm{~L} \mathrm{~kg}^{-1}$ ), 554-4400 $\mathrm{L} \mathrm{kg}^{-1}$ (mean: $2120 \mathrm{~L} \mathrm{~kg}^{-1}$ ) and 653$2590 \mathrm{~L} \mathrm{~kg}^{-1}$ (mean: $1720 \mathrm{~L} \mathrm{~kg}^{-1}$ ), respectively. No SAs or MCs were considered to be accumulated because all BAFs were below $200 \mathrm{~L} \mathrm{~kg}^{-1}$ in aquatic plants. This result showed that CIP was accumulated at high levels in aquatic plants. Several studies reported that high concentrations of CIP were found in aquatic plants (Echinodorus amazonicus) (Chen et al., 2007; Zhang et al., 2009). In addition, plants are able to metabolize ENR into CIP, which may partially explain the high levels CIP in aquatic plants (Migliore, 2003).

\subsection{Antibiotics in animal samples}

The concentrations of antibiotics in animals from Baiyangdian Lake are summarized in Table 1. A total of 18 antibiotics were detected in most animal samples. The total concentrations of antibiotics in biota samples ranged from 13.1 (mallard) to $267 \mu \mathrm{g} \mathrm{kg}^{-1}$ (dw) (crucian carp). Concentrations of $\sum \mathrm{QNs}, \sum \mathrm{SAs}$ and $\sum \mathrm{MCs}$ in animal samples ranged from 17.8 (turtle) to $167 \mu \mathrm{g} \mathrm{kg}^{-1}$ (shrimp), from BDL (turtle, lobster and common carp) to $98.3 \mu \mathrm{g} \mathrm{kg}^{-1}$ (topmouth gudgeon), and from BDL (mallard and Chinese pond heron) to $182 \mu \mathrm{g} \mathrm{kg}^{-1}$ (crucian carp), respectively. MCs and QNs were often detected in these samples. ROX was the dominant compound (BDL-1076 $\mu \mathrm{g} \mathrm{kg}^{-1}$, mean: $52.1 \mu \mathrm{g} \mathrm{kg}^{-1}$ ), followed by NOR (BDL-98.4 $\mu \mathrm{g} \mathrm{kg}^{-1}$, mean: $23.8 \mu \mathrm{g} \mathrm{kg}^{-1}$ ) and OFL (BDL$30.0 \mu \mathrm{g} \mathrm{kg}^{-1}$, mean: $\left.5.58 \mu \mathrm{g} \mathrm{kg}^{-1}\right)$.

PCA was performed to analyze the residual antibiotics in animal samples with high detectable rates, which included five QNs (CIP, ENR, FLE, NOR and OFL), one SA (SMZ), and two MCs (ROX and ERY). The varimax rotation reduced all variables to three different PCs, which represented $81.4 \%$ of the total variance. According to these rules, loadings were situated closely in bit plots representing the variables that were highly correlated. Therefore, PCA was used to identify the correlation among various parameters of pollutants. As shown in Fig. S3, PC1 accounted for $46.6 \%$ of the total variance
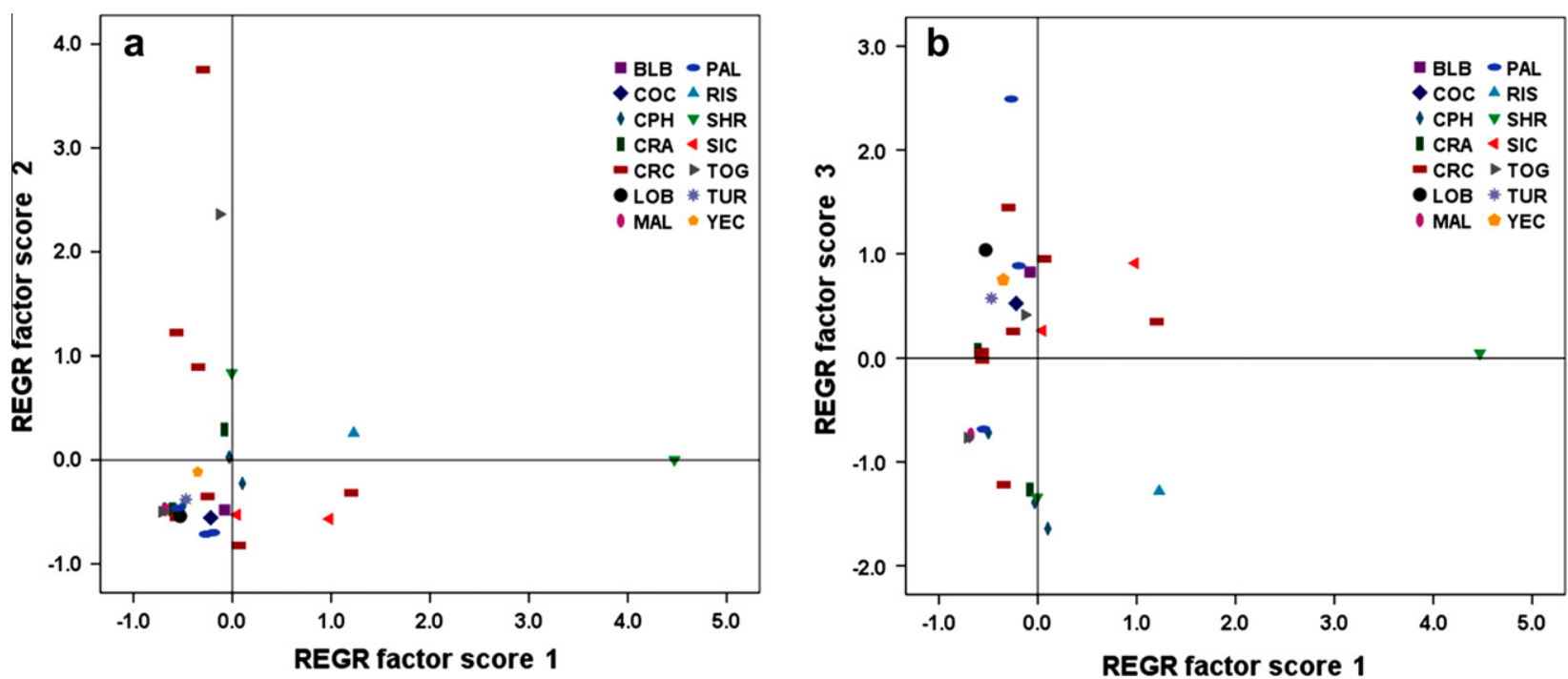

Fig. 4. The score plots of PCA by the database of antibiotics in animals collected from the Baiyangdian Lake in 2008 and 2010. (a) PC1 vs. PC2; (b) PC1 vs. PC3. 
and had strong positive loadings on five QNs; PC2 accounted for $18.0 \%$ of the total variance and had moderately positive loadings for SMZ and ROX; PC3 accounted for $16.9 \%$ of the total variance and had high correlation with ERY. Shrimp, one of the most popular aquatic products in China, had higher loading values of PC1 in the component plot (Fig. 4), indicating that residual QNs were the main antibiotic pollutant in shrimp. In addition, crucian carp and topmouth gudgeon were highly polluted by ROX and SMZ, and parva loach was severely contaminated by ERY (Fig. 4). The high levels of antibiotics in these aquatic animals may reflect their main exposure to antibiotics from lake water or sediment due to their living habits (Zeng et al., 2011). Compared with other animals, antibiotic levels in birds such as Chinese pond heron and mallard were not very high (Fig. S4). However, information on the occurrence and fate of antibiotics in birds was limited (Lemus et al., 2008).

There is limited information on the bioaccumulation potential of pharmaceuticals in biota or food webs (Nikolaou et al., 2007). A previous study has reported that pharmaceuticals in fish can reach significantly higher concentrations in plasma than in ambient water (Fent et al., 2006). BAFs (ratio of the contaminant concentration in animal tissue to ones in water) were calculated for the antibiotics in the 14 species of animal tissues, and some antibiotics were potentially bio-accumulated in these samples (Table S5). ENR was bioaccumulated in shrimp and river snail with mean BAFs of 16600 and $6140 \mathrm{~L} \mathrm{~kg}^{-1}$, respectively; and ROX was accumulated in crucian carp with a mean BAF value of $7410 \mathrm{~L} \mathrm{~kg}^{-1}$. In addition, ENR was potentially bioaccumulated in common carp with a mean BAF value of $4490 \mathrm{~L} \mathrm{~kg}^{-1}$; FLE was potentially bioaccumulated in blunt snout bream and shrimp with mean BAFs of 4130 and $4050 \mathrm{~L} \mathrm{~kg}^{-1}$, respectively; SMZ was potentially bioaccumulated in topmouth gudgeon with a mean BAF value of $3870 \mathrm{~L} \mathrm{~kg}^{-1}$. In general, the bioaccumulation of antibiotics is affected by different factors such as lipid solubility and the octanol-water partition coefficient $\left(K_{o w}\right)$. Antibiotics that are poorly water soluble with $\log K_{o w}>1$ tend to accumulate in organisms (Kümmerer, 2009). It has been reported that BAFs are in accordance with $\log K_{o w}$ s, and antibiotics with low $\log K_{o w}$ values are weakly accumulated in mussel (Le Bris and Pouliquen, 2004). Considering the prediction given by the $\log K_{o w}$ for bioaccumulation, antibiotics with relatively high $\log K_{\text {ow }}$ such as ENR (1.1), FLE (1.08), ROX (2.1-2.8) and SMZ (0.89) were accumulated in animals (Table S6).

Compared with other pharmaceutical and personal care products such as triclosan (BAFs: $27000 \mathrm{~L} \mathrm{~kg}^{-1}$ ) (Kinney et al., 2008) and musk (BAFs: $52370-54070 \mathrm{~L} \mathrm{~kg}^{-1}$ ) (Hu et al., 2011), the BAFs of antibiotics were relative lower. However, in view of the longterm and large scale use of antibiotics, their impact on organisms and environment could not be neglected.

\subsection{Risk assessment}

Previous studies have reported that antibiotics in the aquatic environment may cause adverse ecological and health impacts (Hernando et al., 2006; Jiang et al., 2011). In the present study, antibiotics were frequently found in samples collected from Baiyangdian Lake. Therefore, it is necessary to estimate the ecological risk of these antibiotics using the measured environmental concentrations (MECs) in surface water on organisms.

Acute median effective concentrations $\left(\mathrm{LC}_{50}\right.$ or $\left.\mathrm{EC}_{50}\right)$ of the eight antibiotics to the different aquatic organisms are summarized in Table S7. Algae and plant $\left[\mathrm{L}(\mathrm{E}) \mathrm{C}_{50} \mathrm{~S}: 0.017-50.18 \mathrm{mg} \mathrm{L}^{-1}\right]$ were more sensitive to antibiotics than invertebrate and fish (0.94-562.5 $\mathrm{mg} \mathrm{L}^{-1}$ ). As shown in Table 3, the HQ values of SMX, ERY, SDZ, CIP, and OFL were $31.3,6.0,3.7,3.5$, and 1.5 for algae, respectively, indicating that these antibiotics were harmful to algae in the lake water. This result was consistent with a previous study, which reported that many antibiotics are harmful to algae in freshwater and marine environments (Khetan and Collins, 2007). SMX shows more toxic effects than other compounds on algae (Park and Choi, 2008), and it has been identified as a potentially high risk antibiotics to organisms because it inhibits phagocytic activity at relatively low concentrations (Gagne et al., 2006). As for plant, SMX has a HQ value of 11.6, suggesting its potential adverse ecological consequences on aquatic plants, such as Sal, Cer and Hyd, in Baiyangdian Lake.

From this study, it is obvious that invertebrate and fish are not likely at risk because their HQs are far less than 1. Previous studies have also reported that exposure to antibiotics tend not to affect invertebrate as much as algae (Lützhøft et al., 1999), and fish are

Table 3

Hazard quotients (HQs) for the aquatic organisms as calculated from measured environmental concentrations (MECs) and predicted environmental concentrations (PNECs).

\begin{tabular}{|c|c|c|c|c|c|c|}
\hline Groups & Analytes & Taxonomic group & $\mathrm{L}(\mathrm{E}) \mathrm{C}_{50}\left(\mathrm{mg} \mathrm{L}^{-1}\right)$ & PNEC (ng L ${ }^{-1}$ ) & $\operatorname{MEC}\left(\mathrm{ng} \mathrm{L}^{-1}\right)$ & $\mathrm{HQ}$ \\
\hline \multirow[t]{12}{*}{ QNs } & \multirow[t]{3}{*}{ NOR } & Algae & $50.18(96 \mathrm{~h})$ & 50180 & \multirow[t]{3}{*}{156} & 0.003 \\
\hline & & Plant & $0.913(7 \mathrm{~d})$ & 913 & & 0.171 \\
\hline & & Invertebrate & $194.98(48 \mathrm{~h})$ & 194980 & & 0.001 \\
\hline & \multirow[t]{2}{*}{ CIP } & Algae & $0.017(24 \mathrm{~h})$ & 17 & \multirow[t]{2}{*}{60.3} & 3.544 \\
\hline & & Plant & $0.203(24 \mathrm{~h})$ & 203 & & 0.297 \\
\hline & \multirow[t]{4}{*}{ ENR } & Algae & $0.049(24 \mathrm{~h})$ & 49 & \multirow[t]{4}{*}{4.42} & 0.090 \\
\hline & & Plant & $0.114(24 \mathrm{~h})$ & 114 & & 0.039 \\
\hline & & Invertebrate & $56.7(48 \mathrm{~h})$ & 56700 & & 0.000 \\
\hline & & Fish & $>100(48 \mathrm{~h})$ & 100000 & & 0.000 \\
\hline & \multirow[t]{3}{*}{ OFL } & Algae & $0.021(24 \mathrm{~h})$ & 21 & \multirow[t]{3}{*}{32.6} & 1.551 \\
\hline & & Plant & $0.126(24 \mathrm{~h})$ & 126 & & 0.258 \\
\hline & & Invertebrate & $17.41(48 \mathrm{~h})$ & 17410 & & 0.002 \\
\hline \multirow[t]{6}{*}{ SAs } & \multirow[t]{4}{*}{ SMX } & Algae & $0.03(96 \mathrm{~h})$ & 30 & \multirow[t]{4}{*}{940} & 31.333 \\
\hline & & Plant & $0.081(7 \mathrm{~d})$ & 81 & & 11.605 \\
\hline & & Invertebrate & $15.51(48 \mathrm{~h})$ & 15510 & & 0.061 \\
\hline & & Fish & $562.5(96 \mathrm{~h})$ & 562500 & & 0.002 \\
\hline & \multirow[t]{2}{*}{ SDZ } & Algae & $0.135(72 \mathrm{~h})$ & 135 & \multirow[t]{2}{*}{505} & 3.741 \\
\hline & & Invertebrate & $221(48 \mathrm{~h})$ & 221000 & & 0.001 \\
\hline \multirow[t]{6}{*}{ MCs } & \multirow[t]{3}{*}{ ROX } & Plant & $>1(7 \mathrm{~d})$ & 1000 & \multirow[t]{3}{*}{155} & 0.155 \\
\hline & & Invertebrate & $7.1(96 \mathrm{~h})$ & 7100 & & 0.022 \\
\hline & & Fish & $288.3(96 \mathrm{~h})$ & 288300 & & 0.001 \\
\hline & \multirow[t]{3}{*}{ ERY } & Algae & $0.02(72 \mathrm{~h})$ & 20 & \multirow[t]{3}{*}{121} & 6.042 \\
\hline & & Plant & $>1(7 d)$ & 1000 & & 0.121 \\
\hline & & Invertebrate & $0.94(48 \mathrm{~h})$ & 940 & & 0.129 \\
\hline
\end{tabular}


not likely to be affected (Kümmerer, 2009). Considering bioaccumulation in invertebrate and fish muscles after long-term exposure to antibiotics, the risks of antibiotic contamination of animals need further investigations.

\section{Conclusions}

In the present study, the levels of residue antibiotics were investigated for various samples collected from Baiyangdian Lake. SAs were widely distributed in surface water, QNs were widely distributed in sediments and aquatic plants, and QNs and MCs were widely found in animals. This study showed that antibiotic concentrations are greatly related to anthropogenic activities, and sewage discharge from Baoding City was likely the main source of antibiotics in this lake. Risk assessment of antibiotics on aquatic organism suggested that algae and aquatic plants might be at risk in surface water, while animals were not likely at risk.

\section{Acknowledgements}

This work was supported by the National Natural Science Foundation of China (Nos. 20837003 and 20890111) and the National Basic Research Program of China (2009CB421605).

\section{Appendix A. Supplementary material}

Supplementary data associated with this article can be found, in the online version, at http://dx.doi.org/10.1016/j.chemosphere. 2012.05.079

\section{References}

Batt, A.L., Bruce, I.B., Aga, D.S., 2006. Evaluating the vulnerability of surface waters to antibiotic contamination from varying wastewater treatment plant discharges. Environ. Pollut. 142, 295-302.

Blackwell, P.A., Kay, P., Ashauer, R., Boxall, A.B.A., 2009. Effects of agricultural conditions on the leaching behaviour of veterinary antibiotics in soils. Chemosphere 75, 13-19.

Boxall, A.B.A. Johnson, P., Smith, EJ., Sinclair, C.J. Stutt, E., Levy, L.S., 2006. Uptake of veterinary medicines from soils into plants. J. Agric. Food Chem. 54, 2288-2297.

Brain, R.A., Johnson, D.J., Richards, S.M., Hanson, M.L., Sanderson, H., Lam, M.W., Young, C., Mabury, S.A., Sibley, P.K., Solomon, K.R., 2004. Microcosm evaluation of the effects of an eight pharmaceutical mixture to the aquatic macrophytes Lemna gibba and Myriophyllum sibiricum. Aquat. Toxicol. 70, 23-40.

Chen, J., Zhou, X., Nie, X., Jiang, T., 2007. Fate of Ciprofloxacin in a simulated microcosmos system by different exposure ways. Acta Ecol. Sin. 27, 5300-5307.

Chen, C.Y., Pickhardt, P.C., Xu, M.Q., Folt, C.L., 2008. Mercury and arsenic bioaccumulation and eutrophication in Baiyangdian Lake, China. Water Air Soil Pollut. 190, 115-127.

Cruz Moreno-Bondi, M., Dolores Marazuela, M., Herranz, S., Rodriguez, E., 2009. An overview of sample preparation procedures for LC-MS multiclass antibiotic determination in environmental and food samples. Anal. Bioanal. Chem. 395, 921-946.

Edwards, M., Topp, E., Metcalfe, C.D., Li, H., Gottschall, N., Bolton, P., Curnoe, W., Payne, M., Beck, A., Kleywegt, S., 2009. Pharmaceutical and personal care products in tile drainage following surface spreading and injection of dewatered municipal biosolids to an agricultural field. Sci. Total. Environ. 407, 4220-4230.

EPA, 2007. Method 1694: Pharmaceuticals and Personal Care Products in Water, Soil, Sediment, and Biosolids by HPLC/MS/MS. <http://www.caslab.com/EPAMethods/PDF/1694.pdf>.

Fent, K., Weston, A., Caminada, D., 2006. Ecotoxicology of human pharmaceuticals. Aquat. Toxicol. 76, 122-159.

Gagne, F. Blaise, C., Fournier, M. Hansen, P., 2006. Effects of selected pharmaceutical products on phagocytic activity in Elliptio omplanata mussels. Comp. Biochem. Phys. C 143, 179-186.

Guo, W., Pei, Y.S., Yang, Z.F., Wang, C.H., 2011. Assessment on the distribution and partitioning characteristics of polycyclic aromatic hydrocarbons (PAHs) in Lake Baiyangdian, a shallow freshwater lake in China. J. Environ. Monit. 13, 681-688.

Hernando, M., Mezcua, M., Fernandezalba, A., Barcelo, D., 2006. Environmental risk assessment of pharmaceutical residues in wastewater effluents, surface waters and sediments. Talanta 69, 334-342.

Hu, G.C., Dai, J.Y., Xu, Z.C., Luo, X.J., Cao, H., Wang, J.S., Mai, B.X., Xu, M.Q., 2010. Bioaccumulation behavior of polybrominated diphenyl ethers (PBDEs) in the freshwater food chain of Baiyangdian Lake, North China. Environ. Int. 36, 309-315.
Hu, Z.J., Shi, Y.L., Cai, Y.Q., 2011. Concentrations, distribution, and bioaccumulation of synthetic musks in the Haihe River of China. Chemosphere 84 1630-1635.

Huang, C., Renew, J.E., Smeby, K.L., Pinkston, K., Sedlak, D.L., 2001. Assessment of potential antibiotic contaminants in water and preliminary occurrence analysis. Water Res. 120, 30-40.

Jiang, L., Hu, X., Yin, D., Zhang, H., Yu, Z., 2011. Occurrence, distribution and seasonal variation of antibiotics in the Huangpu River, Shanghai, China. Chemosphere 82, 822-828.

Kan, C.A., Petz, M., 2000. Residues of veterinary drugs in eggs and their distribution between yolk and white. J. Agric. Food Chem. 48, 6397-6403.

Kelly, B.C., Gobas, F.A.P.C., 2001. Bioaccumulation of persistent organic pollutants in lichen-caribou-wolf food chains of Canada's Central and Western Arctic. Environ. Sci. Technol. 35, 325-334.

Khetan, S.K., Collins, T.J., 2007. Human pharmaceuticals in the aquatic environment: a challenge to Green Chemistry. Chem. Rev. 107, 2319-2364.

Kim, S., Carlson, K., 2005. LC-MS ${ }^{2}$ for quantifying trace amounts of pharmaceutical compounds in soil and sediment matrices. TrAC Trend Anal. Chem. 24, 635-644.

Kim, S.D., Cho, J., Kim, I.S., Vanderford, B.J., Snyder, S.A., 2007. Occurrence and removal of pharmaceuticals and endocrine disruptors in South Korean surface drinking, and waste waters. Water Res. 41, 1013-1021.

Kinney, C.A., Furlong, E.T., Kolpin, D.W., Burkhardt, M.R., Zaugg, S.D., Werner, S.L. Bossio, J.P., Benotti, M.J., 2008. Bioaccumulation of pharmaceuticals and other anthropogenic waste indicators in earthworms from agricultural soil amended with biosolid or swine manure. Environ. Sci. Technol. 42, 1863-1870.

Kumar, K., Gupta, S.C., Baidoo, S.K., Chander, Y., Rosen, C.J., 2005. Antibiotic uptake by plants from soil fertilized with animal manure. J. Environ. Qual. 34, 20822085.

Kümmerer, K., 2009. Antibiotics in the aquatic environment-a review-Part I. Chemosphere 75, 417-434.

Le Bris, H., Pouliquen, H., 2004. Experimental study on the bioaccumulation of oxytetracycline and oxolinic acid by the blue mussel (Mytilus edulis). An evaluation of its ability to bio-monitor antibiotics in the marine environment. Mar. Pollut. Bull. 48, 434-440.

Lemus, J.A., Blanco, G., Grande, J., Arroyo, B., Garcia-Montijano, M., Martinez, F. 2008. Antibiotics threaten wildlife: circulating quinolone residues and disease in Avian scavengers. Plos One 3, 1-6.

Luo, Y., Xu, L., Rysz, M., Wang, Y.Q., Zhang, H., Alvarez, P.J.J., 2011. Occurrence and transport of tetracycline, sulfonamide, quinolone, and macrolide antibiotics in the Haihe River Basin, China. Environ. Sci. Technol. 45, 1827-1833.

Lützhøft, H., Halling-Sorensen, B., Jorgensen, S.E., 1999. Algal toxicity of antibacterial agents applied in Danish fish farming. Arch. Environ. Con. Tox 36, 1-6.

Managaki, S., Murata, A., Takada, H., Tuyen, B.C., Chiem, N.H., 2007. Distribution of macrolides, sulfonamides, and trimethoprim in tropical waters: ubiquitous occurrence of veterinary antibiotics in the Mekong Delta. Environ. Sci. Technol. $41,8004-8010$

Matamoros, V., Bayona, J.M., 2006. Elimination of pharmaceuticals and personal care products in subsurface flow constructed wetlands. Environ. Sci. Technol. 40, 5811-5816.

Migliore, L., 2003. Phytotoxicity to and uptake of enrofloxacin in crop plants. Chemosphere 52, 1233-1244.

Moiwo, J.P., Yang, Y., Li, H., Han, S., Yang, Y., 2010. Impact of water resource exploitation on the hydrology and water storage in Baiyangdian Lake. Hydrol. Process. 24, 3026-3039.

Nakata, H., Kannan, K., Jones, P.D., Giesy, J.P., 2005. Determination of fluoroquinolone antibiotics in wastewater effluents by liquid chromatography-mass spectrometry and fluorescence detection. Chemosphere 58, 759-766.

Nikolaou, A., Meric, S., Fatta, D., 2007. Occurrence patterns of pharmaceuticals in water and wastewater environments. Anal. Bioanal Chem. 387, 1225-1234.

Park, S., Choi, K., 2008. Hazard assessment of commonly used agricultural antibiotics on aquatic ecosystems. Ecotoxicology 17, 526-538.

Pei, Y.S., Guo, W., Yang, Z.F., Chen, H., 2011. Historical changes in polycyclic aromatic hydrocarbons (PAHs) input in Lake Baiyangdian related to regional socio-economic development. J. Hazard. Mater. 187, 441-449.

Radjenovic, J., Petrovic, M., Barcelo, D., 2009. Fate and distribution of pharmaceuticals in wastewater and sewage sludge of the conventiona activated sludge (CAS) and advanced membrane bioreactor (MBR) treatment. Water Res. 43, 831-841.

Robinson, A.A., Belden, J.B., Lydy, M.J., 2005. Toxicity of fluoroquinolone antibiotics to aquatic organisms. Environ. Toxicol. Chem. 24, 423-430.

Rosal, R., Rodríguez, A., PerdigónMelón, J.A., Petre, A., GarcíaCalvo, E., Gómez, M.J., Agüera, A., FernándezAlba, A.R., 2010. Occurrence of emerging pollutants in urban wastewater and their removal through biological treatment followed by ozonation. Water Res. 44, 578-588.

Sapkota, A., Sapkota, A.R., Kucharski, M., Burke, J., McKenzie, S., Walker, P. Lawrence, R., 2008. Aquaculture practices and potential human health risks: current knowledge and future priorities. Environ. Int. 34, 1215-1226.

Tamtam, F., Mercier, F., Le Bot, B., Eurin, J., Tuc Dinh, Q., Clément, M., Chevreuil, M., 2008. Occurrence and fate of antibiotics in the Seine River in various hydrological conditions. Sci. Total. Environ. 393, 84-95.

Thuy, H.T., Nga le, P., Loan, T.T., 2011. Antibiotic contaminants in coastal wetlands from Vietnamese shrimp farming. Environ. Sci. Pollut. Res. 18, 835-841.

Tolls, J., 2001. Sorption of veterinary pharmaceuticals in soils: a review. Environ. Sci. Technol. 35, 3397-3406. 
Watkinson, A.J., Murby, E.J., Kolpin, D.W., Costanzo, S.D., 2009. The occurrence of antibiotics in an urban watershed: from wastewater to drinking water. Sci. Total. Environ. 407, 2711-2723.

Yang, J., Ying, G., Zhao, J., Tao, R., Su, H., Chen, F., 2010. Simultaneous determination of four classes of antibiotics in sediments of the Pearl Rivers using RRLC-MS/ MS. Sci. Total. Environ. 408, 3424-3432.

Yang, S.F., Lin, C.F., Lin, A.Y.C., Hong, P.K.A., 2011. Sorption and biodegradation of sulfonamide antibiotics by activated sludge: experimental assessment using batch data obtained under aerobic conditions. Water Res. 45, 3389-3397.

Zeng, L., Wang, T., Wang, P., Liu, Q., Han, S., Yuan, B., Zhu, N., Wang, Y., Jiang, G., 2011. Distribution and trophic transfer of short-chain chlorinated paraffins in an aquatic ecosystem receiving effluents from a sewage treatment plant. Environ. Sci. Technol. 45, 5529-5535.
Zhang, C., Zhou, X., Chen, J., Nie, X., 2009. Dynamics and fate of ciprofloxacin in a simulated aquatic system. J. Ecol. Rural Environ. 25, 73-78.

Zhou, L., Ying, G., Zhao, J., Yang, J., Wang, L., Yang, B., Liu, S., 2011. Trends in the occurrence of human and veterinary antibiotics in the sediments of the Yellow River, Hai River and Liao River in northern China. Environ. Pollut. 159, 1877-1885.

Zhuang, C.W., Ouyang, Z.Y., Xu, W.H., Bai, Y., Zhou, W.Q., Zheng, H., Wang, X.K., 2011. Impacts of human activities on the hydrology of Baiyangdian Lake, China. Environ. Earth Sci. 62, 1343-1350.

Zou, S., Xu, W., Zhang, R., Tang, J., Chen, Y., Zhang, G., 2011. Occurrence and distribution of antibiotics in coastal water of the Bohai Bay, China: impacts of river discharge and aquaculture activities. Environ. Pollut. 159, 2913-2920. 